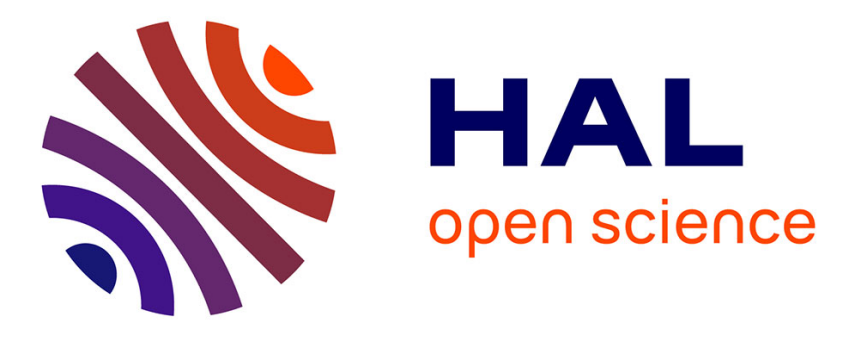

\title{
Indications of bulk property changes from surface ion implantation
}

Peter David Townsend, Yafang Wang, Bairui Yang, Nurdogan Can

\section{To cite this version:}

Peter David Townsend, Yafang Wang, Bairui Yang, Nurdogan Can. Indications of bulk property changes from surface ion implantation. Philosophical Magazine, 2010, 91 (2), pp.259. 10.1080/14786435.2010.518986 . hal-00631269

\section{HAL Id: hal-00631269 https://hal.science/hal-00631269}

Submitted on 12 Oct 2011

HAL is a multi-disciplinary open access archive for the deposit and dissemination of scientific research documents, whether they are published or not. The documents may come from teaching and research institutions in France or abroad, or from public or private research centers.
L'archive ouverte pluridisciplinaire HAL, est destinée au dépôt et à la diffusion de documents scientifiques de niveau recherche, publiés ou non, émanant des établissements d'enseignement et de recherche français ou étrangers, des laboratoires publics ou privés. 


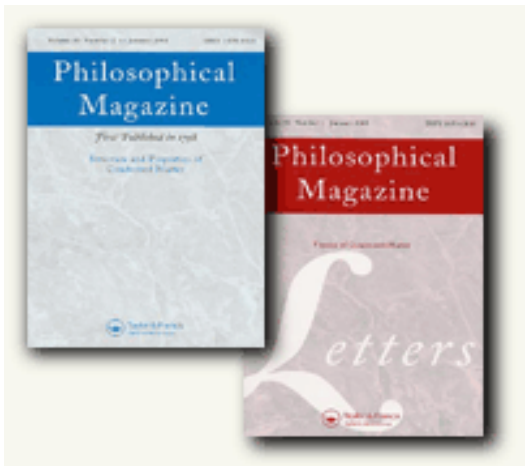

\section{Indications of bulk property changes from surface ion implantation}

\begin{tabular}{|r|l|}
\hline Journal: & Philosophical Magazine \& Philosophical Magazine Letters \\
\hline Manuscript ID: & TPHM-10-Jun-0326.R1 \\
\hline Journal Selection: & Philosophical Magazine \\
\hline Author: & 19-Aug-2010 \\
\hline Complete List of Authors: & $\begin{array}{l}\text { Townsend, Peter; University of Sussex, Science and Technology } \\
\text { Wang, Yafang; China University of Geosciences, School of materials } \\
\text { science and technology } \\
\text { Yang, Bairui; Beijing Normal University, Physics } \\
\text { Can, Nurdogan; Celal Bayar University, Physics }\end{array}$ \\
\hline Keywords: & $\begin{array}{l}\text { insulators, ion implantation, luminescence, optical properties, } \\
\text { radiation effects }\end{array}$ \\
\hline Keywords (user supplied): & implantation effects \\
\hline & \multicolumn{2}{l}{} \\
\hline
\end{tabular}

\section{SCHOLARONE Manuscripts}


1

3

August 192010 Revision after referee comments

\title{
Indications of bulk property changes from surface ion implantation
}

\author{
Y Wang ${ }^{(1)}$, B Yang ${ }^{(2)}$, N Can ${ }^{(3)}$ and P D Townsend ${ }^{(4) *}$ \\ (1) School of Materials Science and Technology, China University of Geosciences, \\ Beijing, 100083, China \\ (2) Physics Department, Beijing Normal University, Beijing 100875, China \\ (3)Physics Department, Celal Bayar University, Faculty of Arts and Sciences, 45140 Manisa- \\ Turkey \\ (4) Science and Technology, University of Sussex, Brighton, BN1 9QH, UK
}

*Electronic mail: pdtownsend@googlemail.com

In the majority of cases the effects of ion implantation are confined close to the implant zone, but potentially the resultant distortions and chemical modifications could catalyse relaxations extending into the bulk substrate. Such possibilities are rarely considered, but the present data suggest that high dose ion implantation of $\mathrm{ZnO}$ has induced bulk changes. Surface implants with $\mathrm{Cu}$ and $\mathrm{Tb}$ strongly modified the low temperature bulk thermoluminescence properties generated by X-ray irradiation. Suggestions are proposed, both for the possible mechanisms for bulk relaxations, and also structural characteristics which may imply where such instability could occur in other lattice structures.

Key words:- thermoluminescence, $\mathrm{ZnO}: \mathrm{Cu}, \mathrm{ZnO}: \mathrm{Tb}$, nanoparticles, phase transitions

PACS Thermoluminescence $78.60 . \mathrm{Kn}$

Phase transitions 64.70.K-

Radiation effects in solids $61.80 .-\mathrm{x}$ 


\section{Introduction}

Ion implantation is a highly successful and ubiquitous tool for the production of semiconductor components $[1,2]$. Additionally there is an extensive literature in many fields for surface modification of other types of material. There are examples ranging widely from optical waveguide and photonic structures in insulators [3], to surface hardening and catalytic effects with metals $[4,5]$, to controlled production of nanoparticles [6]. In all such instances the primary objective has been to induce controllable and desirable changes in the surface of the host materials. Consequently the property changes that are measured focus on surface layers, and to a large extent the possibility that deeper features exist are mostly ignored. However, effects which extend a few microns beyond the implant have been noted, and these are mostly ascribed to the result of induced stress, or exciton and charge trapping. These effects are clearly important as any such distortions or changes of the original lattice will also occur laterally within the surface implant zone in patterned implant devices. By contrast, there has been negligible consideration, or experimental investigation, of the possibility of changes in bulk responses resulting from near surface ion implantation.

\section{Potential materials that could demonstrate long range effects}

Implantation in semiconductors requires small ion doses to achieve control of electrical conductivity, but with increasing ion implant concentrations several other effects develop. A primary factor is radiation damage, in which the structure is perturbed from the original crystalline or amorphous atomic arrangement, and this is 
With insulating materials there are further possible factors as ionisation can cause changes in valence and bond linkages_[7-9]. Similarly, secondary electron ejection will cause locally intense electric fields across the insulating implanted layer. Each of these features will be sensitive to the original stoichiometry and initial degree of perfection in the host material. Potentially, the interface between the implanted and substrate regions can act as a nucleation plane from which relaxations and crystalline transformations can be initiated. Indeed, in annealing of amorphised silicon, the wavefront of crystalline regrowth moves rapidly from the interface through the 
amorphous implant. However, in many materials there is the potential for such seeding of relaxations and phase change to run from the implant zone into the bulk substrate. Obvious candidate materials for such long range lattice relaxations are crystals which intrinsically have a variety of metastable phases and/or are structurally sensitive to variations in stoichiometry, impurities or intrinsic defects. One assumes that bulk changes are most likely to be initially triggered in the highly stressed zone immediately adjacent to the implant region, and then this modified front propagates throughout the crystal. Equally, there may be relaxations driven by electric fields which develop during implantation of insulators.

There are many materials that match these criteria for potential instability. For example in electro-optics and photonics a key material is lithium niobate [10]. It is of value precisely because the lattice is not totally stable, but can be easily deformed by pressure or electric fields. Consequently, it is extremely sensitive in terms of electro optic properties both as the result of dopants, and because it does not grow as a perfect stoichiometric material. Because of the commercial importance of $\mathrm{LiNbO}_{3}$ there has been nearly 50 years of intense effort associated with the crystal growth. Nevertheless, even "stoichiometric" $\mathrm{LiNbO}_{3}$ still has lithium deficiency and a significant vacancy concentration, and the proton exchanged variants have a plethora of phase modifications as a function of temperature and hydrogen doping level.

Lithium niobate is of further relevance here as one can reverse the direction of poling (i.e. the sequence of the $\mathrm{ABCABC}$... structure formed by the $\mathrm{Li}, \mathrm{Nb}$ and structural vacancy) either by heating and applying an electric field across the crystal, 


\section{Techniques to discriminate between surface and bulk property changes}

For insulating materials extremely sensitive measurement techniques include luminescence and Raman studies since they respond to changes in lattice parameters and local defect environments. In order to record changes within an implanted surface region the luminescence excitation can be depth limited to separate the modified and bulk regions. Photoluminescence (PL) may be excited with band gap light so that the signals are generated in a near surface layer. Similarly, by varying the electron energy, 
there is some control over the probe depth of cathodoluminescence (CL). Neither method is a perfect match to the ion implanted volume since both absorption of band gap photons, and electron energy deposition, are strongly depth dependent. Further, depending on ionisation, charge and exciton diffusion, the luminescence can originate at some distance way from the excitation site (typically much less than a micron). Even with such caveats it is simple to record spectral and lifetime changes of the luminescence within ion implanted surfaces of insulators. Data are then interpreted in terms of new localised defect sites, changes in lattice parameters, precipitates and inclusions.

To monitor the luminescence properties of the substrate, without contributions from the implant zone, is more difficult. In principle one may record PL and $\mathrm{CL}_{6}$ from Deleted: 1 the non-implanted surface of the crystal. Alternatively it is possible to record bulk luminescence signals during, or after, excitation with X-rays (RL -radioluminescence or X-ray induced thermoluminescence, (TL)). This is the approach used in the present work for very low penetration of surface implants (a few hundred nanometres) relative to the bulk material (millimetres). Since the implants only directly damage around $\sim 0.01 \%$ of the material one assumes that the RL responses are still totally dominated by the bulk signals. Therefore if one records any significant changes in signal then these are related to bulk modifications caused by surface implants. Experimentally the luminescence signals are viewed from the non-implanted face to avoid any optical absorption within the implant layer.

Detection of such bulk changes from surface implants has been addressed for a 


\section{Experimental details}

Nominally pure $\mathrm{ZnO}$ crystals were obtained from the Shanghai Institute of Optics and Fine Mechanic in China and the Juelich laboratory in Germany. Spectrally resolved thermoluminescence (TL) data were collected with a sensitive thermoluminescence system over the temperature range from 25 to $280 \mathrm{~K}$. The details of this TL spectrometer have been reported before $[14]_{e}$ The signals are corrected for the wavelength dependent sensitivity of the detection system. One key feature of the data collection is that the spectra are taken with a wavelength multiplexed system, which cleanly identifies if different emission bands occur at different temperatures. A $6 \mathrm{~K} / \mathrm{min}$ heating rate was selected to minimize temperature gradients across the samples. Excitation for the TL was with X-rays and all samples were irradiated at 25 $\mathrm{K}$ and the radiation dose was $5 \mathrm{~Gy}$.

Samples were ion beam implanted with either $\mathrm{Cu}$ or $\mathrm{Tb}$ ions using a high ion beam current implanter in Juelich in Germany. The samples were implanted with $400 \mathrm{kev}$ ion energy with different doses (from $1.0 \times 10^{16}$ to $2.5 \times 10^{16}$ ions $/ \mathrm{cm}^{2}$ for $\mathrm{Cu}$ ions, and from $2 \times 10^{16}$ to $2 \times 10^{17}$ ions $/ \mathrm{cm}^{2}$ for $\mathrm{Tb}$ ions). One $\mathrm{Cu}$ sample implanted, with a dose of $1 \times 10^{16}$ ions $/ \mathrm{cm}^{2}$, and a Tb sample with a dose of $2 \times 10^{17}$ ions $/ \mathrm{cm}^{2}$ were 
annealed in the air at $1,000^{\circ} \mathrm{C}$ for one hour. The post implant annealing was primarily intended to remove intrinsic implantation damage. However, within the implant layer such anneals are complicated as copper migration may well occur and, depending on the rate of cooling, copper nanoparticles may form within the layer.

As mentioned, to minimise distortion of the bulk TL signals in implanted samples the implanted face was on the heater block. This avoids absorption of light from the bulk of the crystal within the implant layer. This geometry implies that luminescence signals from the bulk material resulting from the X-ray irradiation should be observable under all circumstances.

The initial assumption would normally be that the bulk TL signal is unaffected by the surface implant and so this will be a constant signal in all samples (both original and implanted). New TL signals may well be generated by the ion implants and reconstruction of the implant $\mathrm{ZnO}$ layer and these will exist as additional features. Experimentally they may be difficult to detect relative to the bulk TL signals since the implant represents merely $\sim 10^{-4}$ of the volume of the total sample, particularly as for our samples there were relatively clear signals from the bulk region.

\section{Results and comments}

Initial material The initial TL measurements contrasted the differences and similarities of samples from the Chinese and German suppliers. An overall isometric view of the TL in terms of spectra and intensity during the TL heating are shown in figure 1. Figure 1a shows isometric data for a German $\mathrm{ZnO}$ sample. The contour map, 
figure $1 \mathrm{~b}$, emphasises that the emission bands differ between the two temperature regions and also that at the higher temperature the "orange" and "red" signals peak at different temperatures. In broad terms there are strong emission features near $40 \mathrm{~K}$ and a weaker set of signals near $160 \mathrm{~K}$. In detail there were minor differences in the low temperature spectra from $\mathrm{ZnO}$ from the two suppliers and a normalised comparison of their emission spectra is shown in figures 2 . The wavelength sensitivity of the TL glow curves is indicated by figures $3 \mathrm{a}$ and $3 \mathrm{~b}$ for material from the two suppliers, in which TL is compared between the Chinese and German material for the spectral bands of 550 to $650 \mathrm{~nm}$ (orange) and 700 to $750 \mathrm{~nm}$ (red).

These results indicate that, although there are minor differences in the emission spectra and TL from material between the two sources, the overall response pattern is similar in both cases. This suggests that the signals originate primarily from intrinsic type luminescence sites of the $\mathrm{ZnO}$.

Effects of ion implantation Figure 4 offers examples of TL performance from ion implanted $\mathrm{ZnO}$. Figure $4 \mathrm{a}$ is a TL plot of a sample implanted with $\mathrm{Cu}$ to a dose of 2.5 $\times 10^{16}$ ions $/ \mathrm{cm}^{2}$ and figure $4 \mathrm{~b}$ shows the effect from using a dose of $2.0 \times 10^{16}$ ions $/ \mathrm{cm}^{2}$ of $\mathrm{Tb}$ ions. Visually the two images are very similar but the more detailed TL plots for the two main emission band regions show some slight differences in terms of the relative heights of the bands. Figure $5 \mathrm{a}$ is for the $\mathrm{Cu}$ data and figure $5 \mathrm{~b}$ is for the Tb implant.

Despite small differences between $\mathrm{Cu}$ and $\mathrm{Tb}$ samples it is clear that neither 
isometric plot resembles that taken for unimplanted samples (as in figure 1a). In particular the low temperature signals have been completely suppressed, and the red signals seen near $140 \mathrm{~K}$ have become very intense. The original red bands near 700 $\mathrm{nm}$ have been replaced with a feature at slightly longer wavelengths of $\sim 730 \mathrm{~nm}$. On more careful inspection one notes that for the higher temperature peaks the orange and red features occur at different temperatures, with the $550 \mathrm{~nm}$ emission preceding the $730 \mathrm{~nm}$ glow peak by $\sim 15$ degrees.

Post implant annealing One sample, which had received a smaller ion dose of $1 \times 10^{16}$ ions $/ \mathrm{cm}^{2}$ of copper was annealed at $1,000^{\circ} \mathrm{C}$ to test if the changes in TL response were sustained after annealing. The isometric data are shown in figure 6 and spectrally resolved TL plots are presented in figure $7 \mathrm{a}$ and $7 \mathrm{~b}$ are for orange and red emission. Signals for the original unimplanted $\mathrm{ZnO}$ are included for comparison.

Whilst there are now signals at the lower temperatures after the annealing treatment, the form of the glow curves and the position of the emission bands are significantly different from the original data. Annealing has added new complexity to the signals, rather than just regenerating the pre-implant data. Annealing has however retained a strong red emission peak, even though it has moved in TL temperature.

\section{Discussion}

The objective of this experiment was to consider if high dose surface implants, with penetration depths of a few hundred nanometres, have any detectable influence 
on the bulk luminescence signals of $\mathrm{ZnO}$ crystals. The advantages of the $\mathrm{x}$-ray excited low temperature TL is that the measurement does not introduce any thermal heating after the implantation and, since the implant volume is only $\sim 10^{-4}$ of the sample volume, the bulk signals should be retained. New TL features from within the implant volume may exist, but such signals may be overshadowed by the bulk signals. The reality is that the surface implants have totally modified the bulk signals, as is seen by comparing figures 1 and 4 . This is extremely clear evidence that the bulk $\mathrm{ZnO}$ is showing different TL response to the X-ray excitation.

Whilst these data satisfy our original objective of demonstrating very long range effects in an insulator as the result of surface implants, the results do not reveal the mechanism for the change, nor the precise changes which have occurred. The discussion of the mechanisms and modifications which occur must therefore be very speculative. Nevertheless, the detection of such changes has significant implications for consideration of ion implantation in many types of material.

This is not the first demonstration of such effects as we have conducted quite detailed studies of luminescence signals from strontium titanate [1ㅁ-13]. The $\mathrm{SrTiO}_{3}$ case was perhaps less surprising as it is known to be structurally very sensitive to impurities and growth conditions, and the relevant literature has many anomalies and conflicts as to how many low temperature phase transition, or relaxations, can occur. Therefore the interpretation for $\mathrm{SrTiO}_{3}$ was that stress generated from the implant layer was sufficient to induce phase changes. Further, there were discontinuities in the temperature dependence of the luminescence signals, which are characteristic 
signatures of phase transitions, and indeed they occurred at temperatures which matched critical points discussed in the strontium titanate literature.

For $\mathrm{ZnO}$ it is less obvious if there have been any phase changes as there are no discontinuities in the luminescence signals with temperature. This does not exclude the possibility that the lattice parameter has not been modified, or that stress or electric field derived from the implant zone have not introduced asymmetry into the lattice structure. Volume and distortion changes in the lattice will of course modify the intrinsic (and impurity) luminescence sites and will shift the glow peak temperatures. Such TL peak shifts as a function of lattice distortion have already been reported in several other insulating materials.

$\mathrm{ZnO}$ was chosen for this experiment as it is unlikely to be fully stoichiometric $[15]$ Deleted: ${ }^{18}$ and it is known from the higher temperature studies that it can relax under high pressure and even undergo phase transitions, deform readily and is sensitive to impurities [16-18] The normal material is a hexagonal (wurtzite) structure but cubic variants have been formed. For non-stoichiometric or impure material, lattice perfection is suspect. Interestingly, it has been claimed that $\mathrm{ZnO}$ can form the richest family of nanostructures [19], The excellent non-linear and piezo- or electro-optic Deleted: ${ }^{9}$ properties also imply structure with the potential to readily distort. Similarly the measurement of photoluminescence or cathodoluminescence has generated a literature where the emission spectra are extremely varied both in terms of peak position, substructure, and different relative intensities of the nominal green and red emission bands. Variations are invariably a key indicator that the materials are non-

Deleted: ${ }^{20-22}$

Deleted: Such

Deleted: v 
stoichiometric, distorted or contain a variety of defect clusters and/or impurities. Such situations therefore have the potential for the crystal to distort and relax into alternative stable zones under stress or electric fields.

In terms of luminescence efficiency and the types of defect which contribute to the TL signals it is essential to note that the older models of highly localized defects are inappropriate (e.g. as reviewed in [20]) Instead one must recognize that luminescence efficiency is strongly influenced by many neighbouring shells of lattice ions. The more sensitive experiments and calculations suggest that "point" defects can influence many thousands of neighbouring ion sites. Thus distortions of the local symmetry, for example by a uniaxial stress induced from the implant surface, relaxations of the basic lattice spacing, or even, in an extreme case conversion to a new crystalline phase, would all change the emission site properties. This would be reflected by changes in emission spectra and shifts in the glow peak temperatures, as seen here for $\mathrm{ZnO}$. The parallel experiments with $\mathrm{SrTiO}_{3}$ identified that, at least in that lattice, the ion implantation stress can induce phase transitions. Equally clear is that in many materials long range effects exist from phase changes of nanoparticle inclusions. In each situation there are changes in luminescence efficiency and emission spectra, The use of luminescence to detect such phase transitions and relaxations has recently been reviewed [21, 22].

The temperatures at which glow peaks occur are similar to the critical temperatures at which ESR defects anneal or convert into different species. In particular the lowest temperature signals match to charge release of holes as
Deleted: 1

Deleted: ${ }^{23}$

Deleted: ${ }^{1,2}$

Deleted: 1

Deleted: 1

Formatted: Default Paragraph Font, English (U.K.)

Formatted: Default Paragraph Font, English (U.K.)

Formatted: Indent: First line: $21 \mathrm{pt}$, Line spacing: Double 
interstitial diffuse [23-27]. Signals in the region of $150 \mathrm{~K}$ have been linked to annealing of oxygen vacancy $\left(\mathrm{V}_{\mathrm{O}}\right)$ centres. All three charge states of $\mathrm{V}_{\underline{\mathrm{O}}}, \mathrm{V}_{\mathrm{O}}{ }^{+}, \mathrm{V}_{\underline{O}}{ }^{2+}$ have been reported, and the $\mathrm{V}_{\mathrm{O}}{ }^{+}$decays into a $\mathrm{V}_{\mathrm{O}}$ with an activation energy of $\sim 0.3 \mathrm{eV}$,

\section{$[27,28]$ corresponding to TL activation energy of the $150 \mathrm{~K}$ type features.}

In terms of spectra the emission bands noted during the TL measurements are broadly consistent with luminescence bands discussed elsewhere for $\mathrm{ZnO}$ and which are generally ascribed to intrinsic defects. Nevertheless the literature, although extensive (e.g. $[15,19,23-37])$ is not totally satisfactory, as a large fraction of the studies which mention luminescence relate to thin film or particulate size $\mathrm{ZnO}$, or material which is doped. The films and small particle work is thus biased by problems of non-stoichiometry and the importance of surfaces and grain boundaries. Both green and yellow emission bands are cited with varying models based on intrinsic, or intrinsic plus impurity, sites. The features seen here near $590 \mathrm{~nm}$ might fit to the "yellow" emission bands but there are obviously a number of component features. There have been studies of copper doping in $\mathrm{ZnO}$ [29] which activates green emission near $510 \mathrm{~nm}$. For our copper implanted samples recorded there is no obvious enhancement of emission in that range. Indeed since the copper would be confined to the tiny implant surface zone any such X-ray stimulated TL signals would be very small compared with those from the bulk material. One also notes that the spectra from $\mathrm{Cu}$ and $\mathrm{Tb}$ implants were very similar, so it is lattice damage that is important for this data.
Formatted: Default Paragraph Font, English (U.K.)

Formatted: Default Paragraph Font, English (U.K.)

Formatted: Default Paragraph Font, English (U.K.)

Formatted: Default Paragraph Font, English (U.K.)

Deleted: $\mathbb{I}$

Formatted: English (U.S.)

Deleted: 2

Deleted: 14

Deleted: ${ }^{7}$ 


\section{References}

1. P.Y. Yu and M. Cardona, Fundamentals of semiconductors, Springer Verlag, Berlin (2010) pp 775.

\section{Ion implantation in semiconductors, Editors D. Stievenard and J.C. Bourgoin,}

Trans-tech Publications, Zurich (1991) pp.480.

3. P.D. Townsend, P.J. Chandler and L. Zhang, Cambridge University Press,

Cambridge, (2006) pp. 280.

4. G. Dearnaley, Nature, 256 (1975) p.701; ibid Thin Solid Films 107 (1983) p.315.

5. S.T. Picraux, Ann. Rev. Mat. Sci., 14 (1984) 335.

Formatted: Line spacing: Double, Tabs: 18 pt, Left

Formatted: Line spacing: Double

Formatted: Font: $12 \mathrm{pt}$

Formatted: Font: $12 \mathrm{pt}$

Formatted: Font: $12 \mathrm{pt}$

Formatted: Line spacing: Double, Tabs: $18 \mathrm{pt}$, Left

Formatted: Line spacing: Double

Formatted: Font: $12 \mathrm{pt}$

Formatted: Font: $12 \mathrm{pt}$ 
$\underline{\text { 6. Ion beams in nanoscience and technology, Editors R. Hellborg, H.J. Whitlow and }}$

Y. Zhang, Springer, Berlin, (2009) pp. 457.

7. W. Hayes and A.M. Stoneham, Defects and defect processes in non-metallic solids, Wiley, New York, (1985) pp 472.

8. F. Agullo-Lopez, C.R.A. Catlow and P.D. Townsend, Point defects in Materials,

Academic Press, London (1988) 445.

9. A. Kelly, G. W. Groves and P. Kidd, Crystallography and crystal defects, Wiley,

Chichester (2000) pp. 470.

10. Properties of lithium niobate, Editor S.C. Abrahams, INSPEC, London, (1989),

pp 359.

11. B. Yang, P.D. Townsend and R. Fromknecht, J. Phys.: Condens. Matter 16 (2004)

Formatted: Font: $12 \mathrm{pt}$ p. 8377.

12. B. Yang, P.D. Townsend and R. Fromknecht, Nucl. Inst. Methods B 217 (2004) p. 60.

13. B. Yang, P.D. Townsend and R. Fromknecht, Nucl. Inst. Methods B 226 (2004) p. 549.

14. B.J. Luff and P.D. Townsend, Meas. Sci. Technol. 4 (1993) p. 65.

15. A. Ashrafi and C. Jagadish, J. Appl. Phys 102 (2007) p. 071101.

16. S.O. Kucheyev, J.E. Bradby, J.S. Williams and C. Jagadish, Appl. Phys. Letts. 80 $(2002)$ p. 256 .

17. S.K. Kim, S.Y. Jeong and C.R. Cho, Appl. Phys, Letts, 82 (2003) p. 562.

18. Y. Chen, Y. Runzhou, S. Qian, J. Qin, and F. Zheng, Materials 61 (2007) p. 4438.

\begin{tabular}{|l|}
\hline Deleted: \\
\hline Formatted: Font: $12 \mathrm{pt}$ \\
\hline Deleted: $\mathbb{I}$ \\
\hline Formatted: Font: $12 \mathrm{pt}$ \\
\hline
\end{tabular}


19. Zhong Lin Wang, J. Phys Condensed Matter 16 (2004) p. R829.

20. P.D. Townsend, J. Phys.: Condens. Matter, 13 (2001) p. 2211.

21. P.D. Townsend, B. Yang and Y. Wang, Contemporary Physics 49 (2008) p. 255.

22. P.D. Townsend, B. Yang and Y. Wang, Revista Mexicana de Fisica S54 (2008) p. 29 .

23. W.E. Carlos, E.R. Glaser and D.C. Look, Physica B 308-310 (2001) p.976.

24. A.F. Kohan, G. Ceder, D. Morgan and C.G. Van de Walle, Phys. Rev. B. 61 (2000) p. 15019

25. D.C. Look, C. Coskun, B. Claflin and G.C. Farlow, Physica B, 340-342 (2003) p. 32 .

26. F. Sun, C.X. Shan, S.P. Wang, B.H. Li, J.Y. Zhang, Z.Z. Zhang, D.X. Zhao, B. Yao, D.Z. Shen and X.W. Fan, Appl. Surf. Sci. 256 (2010) p. 3390.

\section{L.S. Vlasenko, G.D. Watkins, Phys. Rev. B 71 (2005)_p. 125210.}

28. K. Vanheusden, L. Warren, C.H. Seager, R. Tallant, J.A.. Voigt and B.E. Gnade, J Appl Phys 79 (1996) p. 7983.

29. N.Y. Garces, L. Wang, L. Bai, N. C. Giles, L. Halliburton and G. Cantwell, G Appl. Phys Letts 81 (2002) p. 622.

30, P.S. Xu, Y. M. Sun, C.S. Shi, F.Q. Xu and H B. Pan, Nucl. Inst. Methods B 199 (2003) p. 286.

31. A. Janotti, C. G. Van de Walle, Appl. Phys Letts 87 (2005) p. 122102

32. Y.W. Heo, D.P. Norton and S.J. Pearton, J. Appl. Phys 98 (2005) p. 073502.

33, U. Ozgur, Ya.I. Alivov, C. Liu, A. Teke, M.A. Reschikov, S. Dogan, V. Avrutin,
Deleted: 1

Deleted: 1

Deleted: 1

Formatted: Font: $12 \mathrm{pt}$

Formatted: Line spacing: Double

Formatted: Font: $12 \mathrm{pt}$

Formatted: Font: $12 \mathrm{pt}$

Formatted: Font: $12 \mathrm{pt}$

Deleted: 1

Deleted: 3

Formatted: Font: $12 \mathrm{pt}$

Deleted: II

Formatted: Font: $12 \mathrm{pt}$

Deleted: 14

Deleted: 15

Deleted: 16

Deleted: II

17

Deleted: L.S. Vlasenko, G.D.

Watkins, Phys. Rev. B 71 (2005) p. 125210.

Deleted: 18

Deleted: 19 
S.J. Cho and H. Morkoc, J. Applied Phys 98 (2005)_p. 041301.

34. F. Tuomisto, K. Saarinen, D.C. Look and G.C. Farlow, Phys. Rev. B 72 (2005) p. 085206 .

35. T.M. Borseth, B.G. Svensson, A.Yu Kuznetsov, P. Klason, Q.X. Zhao and M. Willander, Appl. Phys Lett. 89 (2006) p. 262112.

36. A.B. Djurisic and Y.H. Leung, Small 2 (2006) p. 944.

37. Lin Yow-Jon, Tsai Chia-Lung, Lu Yang-Ming and Liu Chia-Jyi, J. Appl. Phys 99 (2006) p. 093501.
Formatted: Font: $12 \mathrm{pt}$

Deleted: 20

Formatted: Font: $12 \mathrm{pt}$

Deleted: 21

Deleted: 22

Deleted: 23 
2

3

4

5

6

7

8

9

10

11

12

13

14

15

16

17

18

19

20

21

22

23

24

25

26

\section{Figure captions}

Figure 1 Low temperature thermoluminescence from $\mathrm{ZnO}$ after X-ray irradiation at $25 \mathrm{~K}$ for a heating rate of $6 \mathrm{~K} /$ minute. (a) an isometric view and (b) a contour map which emphasizes that different spectral regions peak in intensity at different temperatures.

Figure 2 Comparisons of $40 \mathrm{~K}$ TL emission spectra from samples from different suppliers.

Figure 3 Wavelength resolved $\mathrm{ZnO}$ TL curves for the orange and red emission regions. (3a) is for a Chinese sample and (3b) for one from Germany.

Figure 4 The isometric view of the TL emission after the surface had been implanted with high doses of (a) $\mathrm{Cu}$ and (b) $\mathrm{Tb}$ ions.

Figure 5 Examples of wavelength resolved TL for implanted samples, (a) after $\mathrm{Cu}$ implantation and (b) after Tb implants.

Figure 6 The glow curve of a copper implanted annealed $\mathrm{ZnO}$ sample.

Figure 7 Spectrally resolved TL for (a) orange and (b) red emission of $\mathrm{ZnO}$ for three stages of treatment. The plots include TL of an original crystal, data for a $\mathrm{Cu}$ implanted sample, and the TL patterns seen after a $\mathrm{Cu}$ implanted sample had been annealed. 
June 302010

\section{Indications of bulk property changes from surface ion implantation}

Y Wang ${ }^{(1)}$, B Yang ${ }^{(2)}$, N Can ${ }^{(3)}$ and P D Townsend ${ }^{(4)^{*}}$

\section{Figures}


Figures and captions

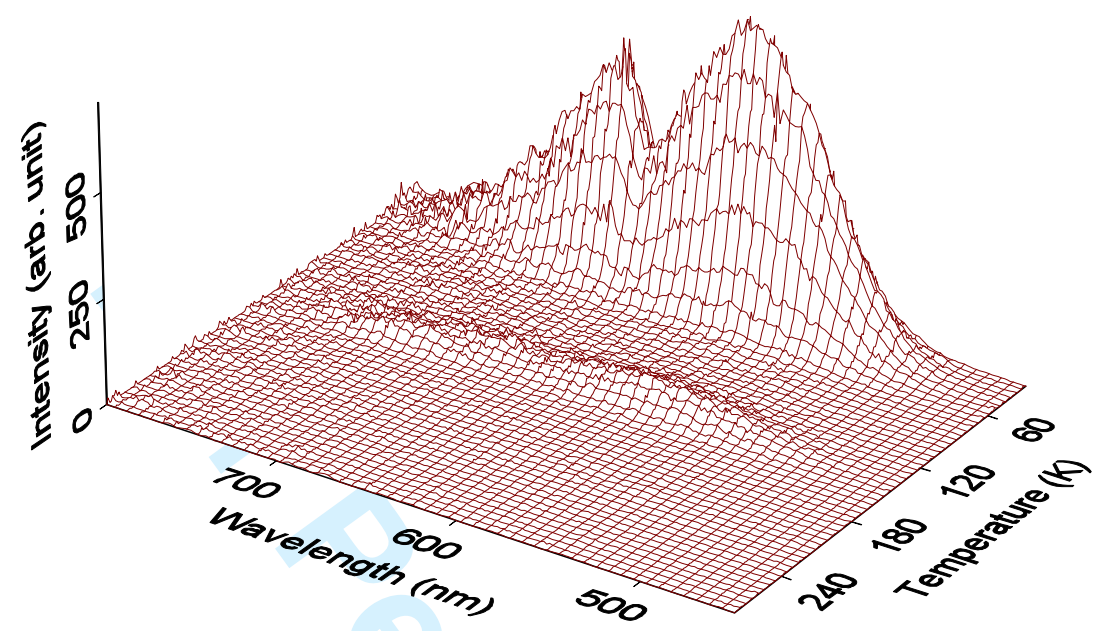

Fig 1a

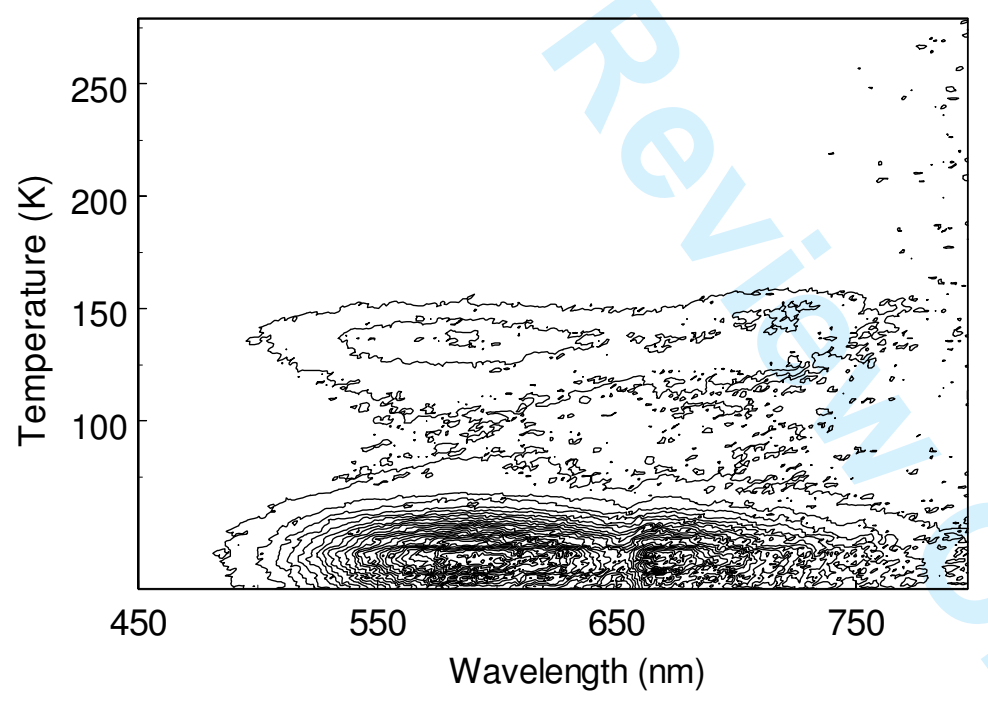

Fig $1 b$ 


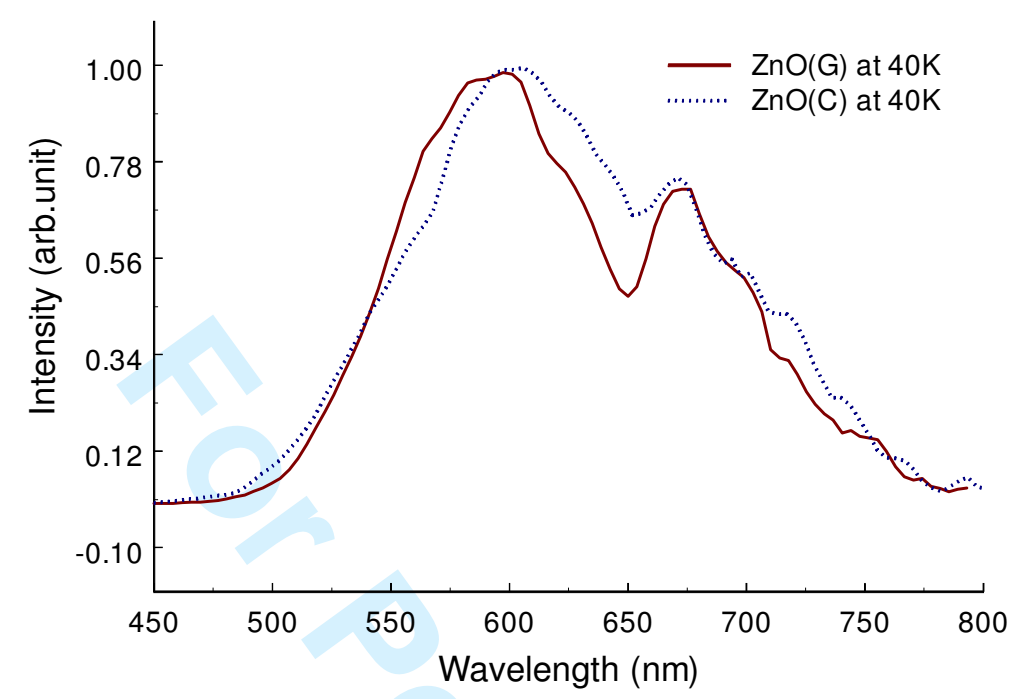

Figure 2 


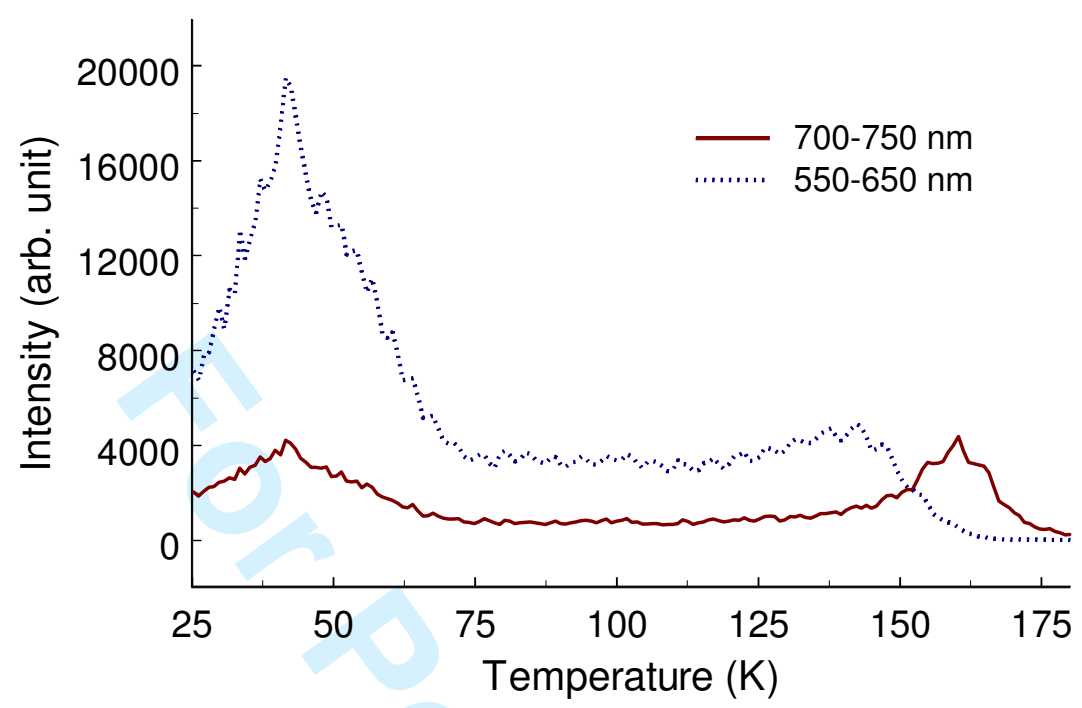

Fig 3a

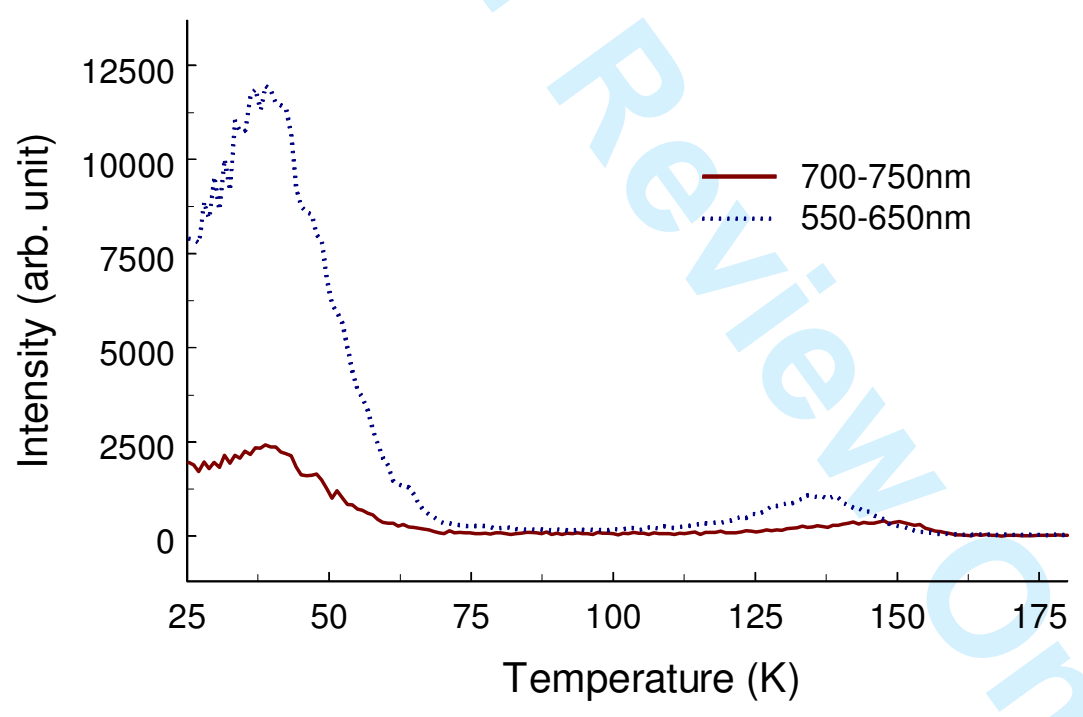

Fig $3 b$ 


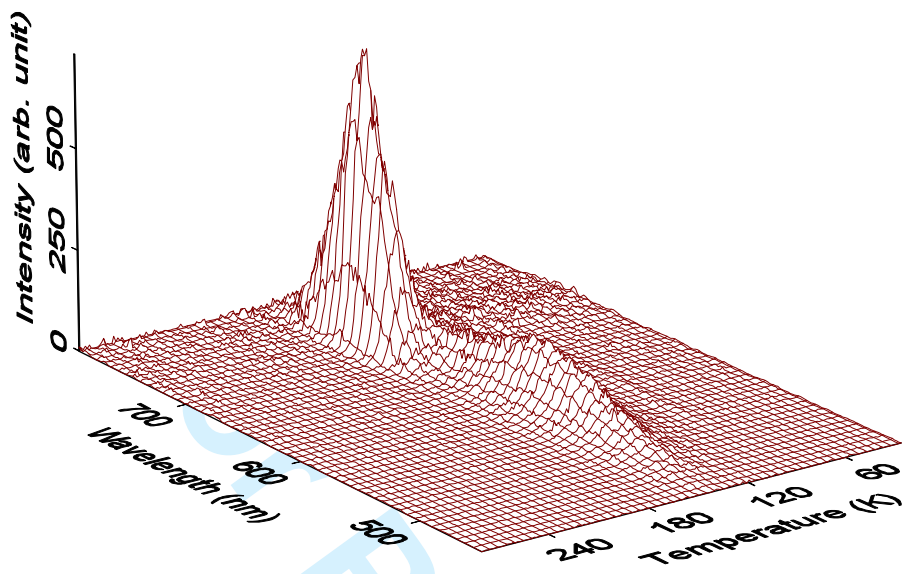

Fig 4a

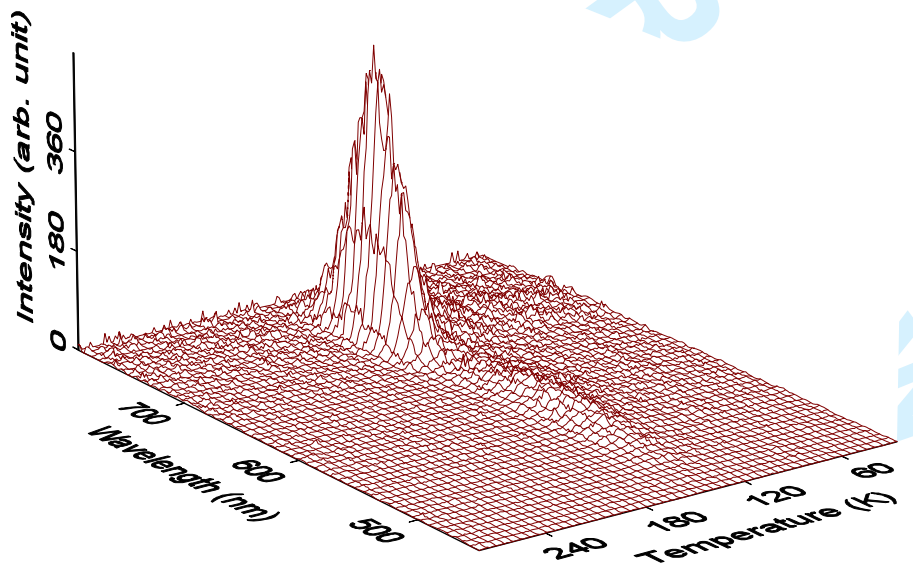

Fig 4b 


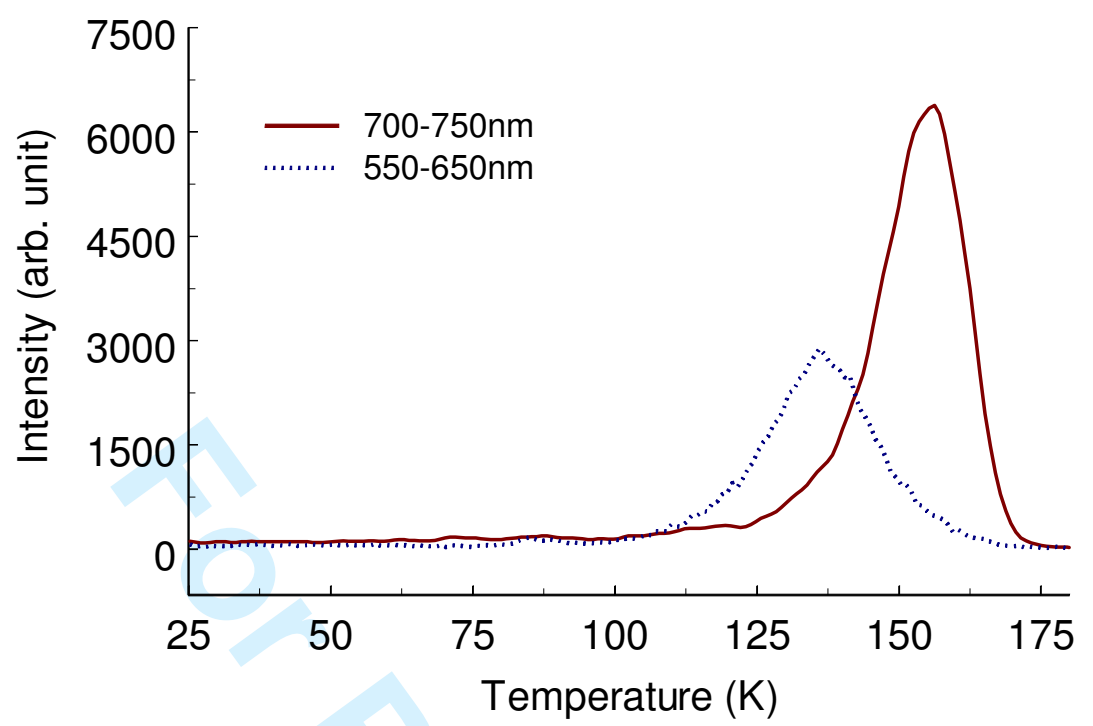

Fig 5a

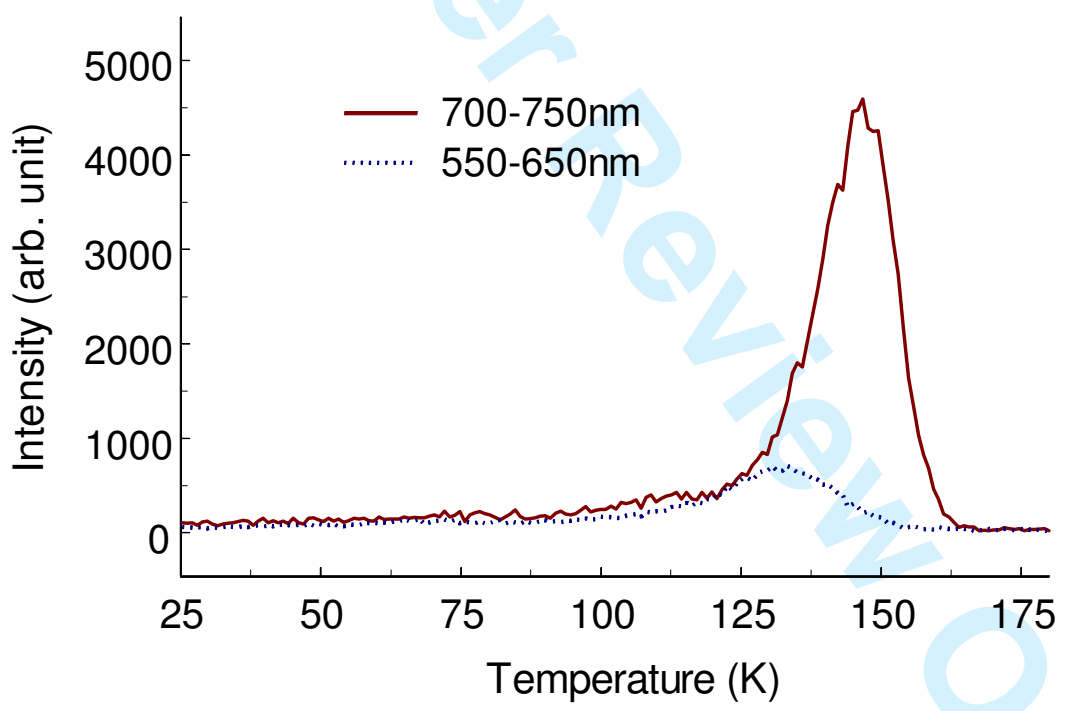

Fig $5 b$ 


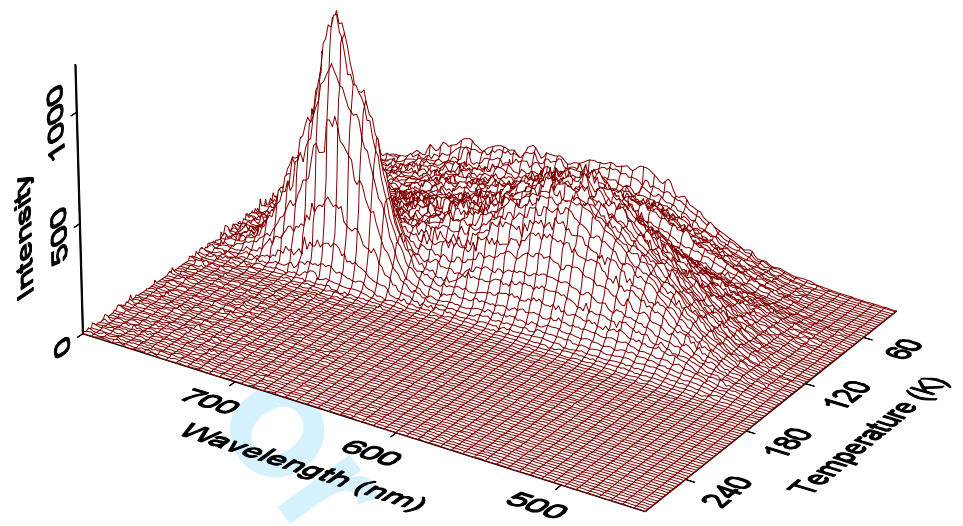

Figure 6 


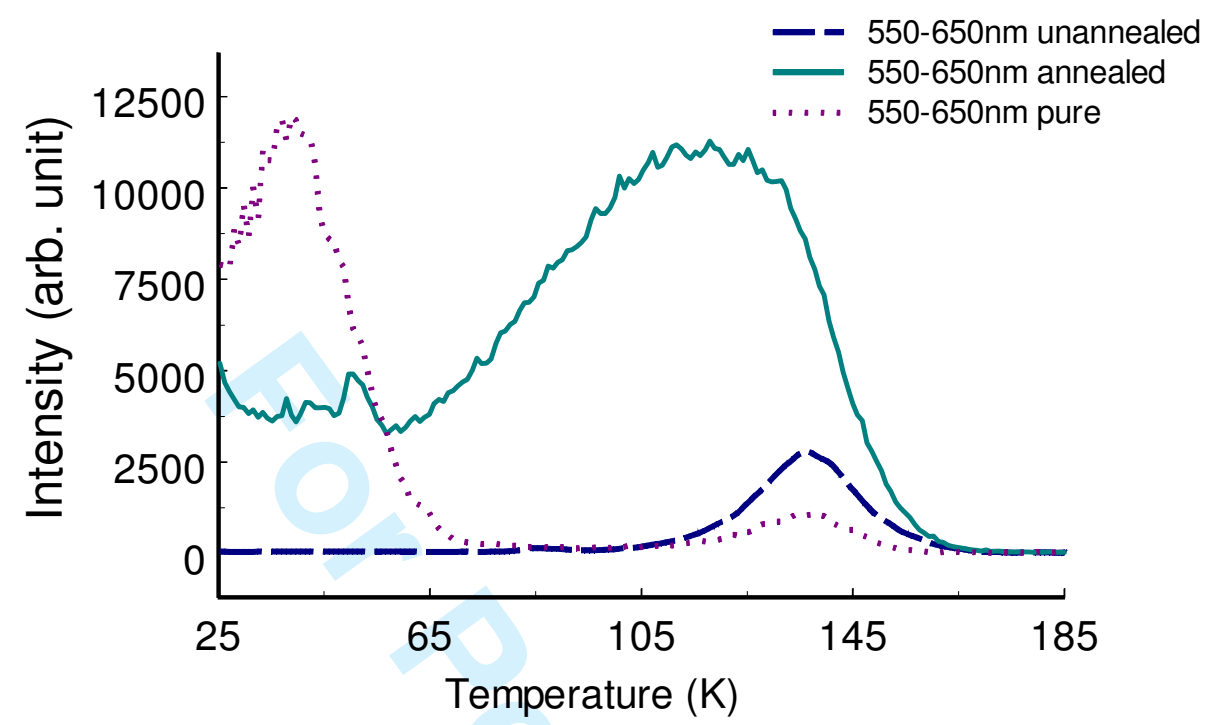

Fig $7 \mathrm{a}$

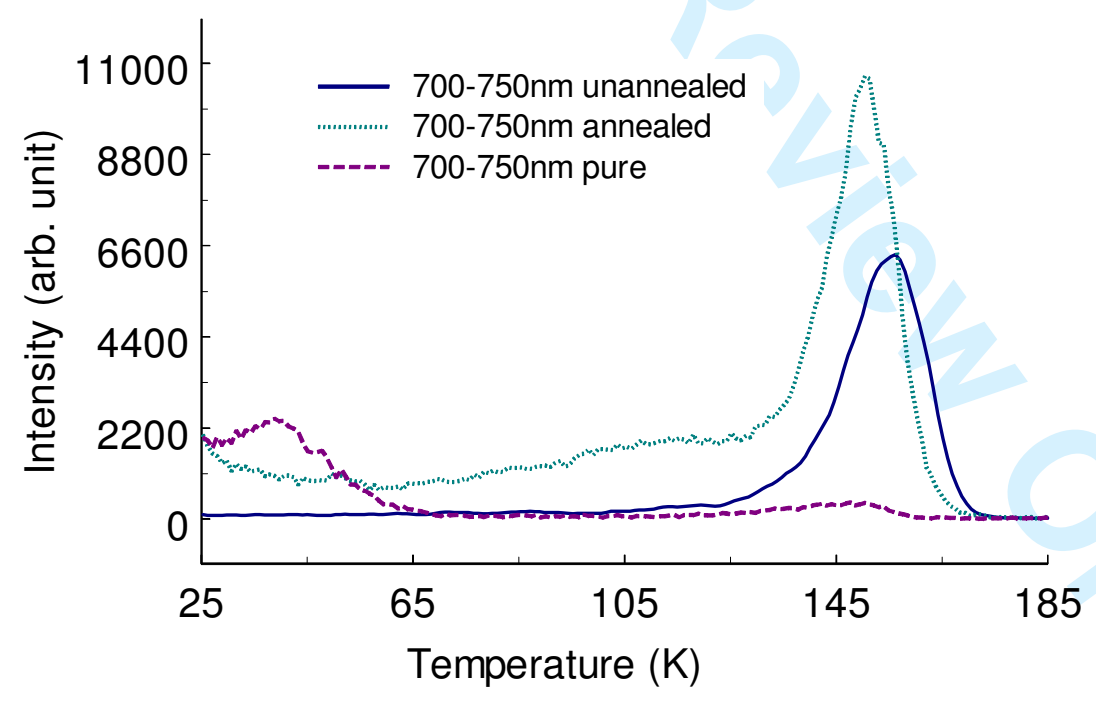

Fig $7 b$ 